\title{
Motivational Basis of Dissonance: The Singular Role of Behavioral Consequences
}

\author{
Steven J. Scher and Joel Cooper \\ Princeton University
}

\begin{abstract}
This article provides the first empirical test of the idea that discrepancy is not needed in order to arouse cognitive dissonance. Dissonance was aroused when Ss felt responsible for some aversive consequence, regardless of whether their behavior was consistent (writing a proattitudinal essay) or inconsistent (a counterattitudinal essay) with beliefs. The data demonstrate that in both situations, dissonance is aroused. This result, based on the dissonance motivation model of Cooper and Fazio (1984), strongly suggests that the motivational basis for dissonance is the felt responsibility for aversive consequences. The theoretical implications of this outlook are explored, including a discussion of the many ways that it expands the applicability of dissonance theory.
\end{abstract}

One of the most frequently demonstrated phenomena in social psychology is that people who act in a way that is inconsistent with their attitudes experience a motivational state that causes them to alter those attitudes. The primary theoretical explanation for this motivation has been Festinger's (1957) theory of cognitive dissonance. This theory is based on a principle of cognitive consistency and assumes that an aversive, drivelike state is aroused when cognitive inconsistency is perceived. Attitude change follows, then, as a means of restoring consistency and reducing the aversive state.

Dissonance theory has been able to account for a host of phenomena, ranging from the proselytizing behavior of religious cultists (Festinger, Riecken, \& Schachter, 1956) to the toy preferences of small children (Aronson \& Carlsmith, 1963). However, the induced compliance paradigm, in which subjects are induced to argue a position that is counterattitudinal, has most frequently been the tool of choice for experimental research in this area. Consider the following situation: A teacher plays the devil's advocate in a class, advocating, for instructional purposes, a position with which he or she actually disagrees. According to Festinger's (1957) theory, the inconsistency between the teacher's action in the class and his or her true attitude should produce pressure for attitude change in the direction of the teacher's pedagogical arguments.

Research since the initial formulation of dissonance theory, however, has identified a number of parametric limitations on the likelihood that the teacher would experience dissonance and change his or her attitude: The inconsistent behavior must be freely chosen (Davis \& Jones, 1960; Linder, Cooper, \& Jones, 1967; Sherman, 1970b), there must be some commitment to

This research was conducted while Steven J. Scher was supported by National Institute of Mental Health Grant 5T32MH18021-03.

The authors would like to thank Linda Ginzel, E. E. Jones, Pamela Kato, and Dale Miller for their helpful comments on an earlier version of this article.

Correspondence concerning this article should be addressed to Joel Cooper, Department of Psychology, Princeton University, Princeton, New Jersey 08544. the behavior (Carlsmith, Collins, \& Helmreich, 1966), some aversive or undesired consequence must result from the behavior (Collins \& Hoyt, 1972; Cooper \& Worchel, 1970), and this consequence must have been foreseen or foreseeable (Cooper \& Goethals, 1974; Goethals, Cooper, \& Naficy, 1979; Sherman, 1970a).

These increasing limits to the conditions under which counterattitudinal advocacy leads to attitude change strained the limits of the original inconsistency-based explanation of the induced compliance phenomenon. Subsequently, several attempts were made to develop a more parsimonious theoretical explanation for these findings (see Greenwald, Pratkanis, Leippe, \& Baumgardner, 1986, for a discussion of the role of limiting conditions in theory revision). For example, several theorists have argued that inconsistency in behavior leads to counterattitudinal attitude change because acting inconsistently implies a trait (e.g., dishonesty or stupidity) that is strongly discrepant with one's self-image (e.g., Aronson, 1969; Greenwald \& Ronis, 1978) or with the impression one wants to project to the outside world (Tedeschi, Schlenker, \& Bonoma, 1971).

Cooper and Fazio (1984) argued for the value of taking a completely new look at the motivational properties of dissonance. They argued that the abhorrence of inconsistency was not the motivational basis of dissonance. Rather, taken together, the limiting conditions we have identified above seem to be the same conditions that would lead one to make an attribution of self-responsibility for some aversive consequence that might be produced (cf. Cooper \& Scher, in press).

In this article, we adopt the point of view that dissonance is not motivated by inconsistency. Rather, it is the aversiveness of some consequence that produces dissonance. To the extent that inconsistent actions do bring about aversive consequences, such actions will produce dissonance; however, such inconsistency is neither necessary nor sufficient for dissonance to be aroused. The teacher in our example would experience dissonance (and attitude change) not merely because an inconsistent argument was made, bait because that argument caught actually convince some naive students to believe something that the teacher would not want them to believe. 
In the Cooper and Fazio (1984) model, dissonance motivation occurs only when people notice that they have brought about an aversive event. This then activates a search for responsibility. If an attribution of self-responsibility is made, dissonance is aroused. Once dissonance is aroused. the individual must seek to change perceptions either about the consequences or about self-responsibility. When the situation precludes the latter (cf. Calder, Ross, \& Insko, 1973), it is likely that the individual will try to change perceptions about the aversiveness of the consequences. This can often be accomplished by changing attitudes about the outcome, which will make the consequences less aversive. If the teacher comes to believe the "devil's advocacy," then the fact that the students now believe this position would no longer be undesirable.

A clear implication of this reasoning is that an aversive event that was created in a way that did not involve counterattitudinal advocacy would nonetheless lead to dissonance arousal. There have been no direct tests of this proposition, although it is the crucial element of the Cooper and Fazio (1984) model and has been claimed to be true by some for almost 2 decades (e.g., Collins, 1969; Hoyt, Henley, \& Collins, 1972).

There have been a number of experimental tests of the corollary of this point: Dissonance is aroused only when counterattitudinal advocacy leads to the production of some aversive consequence. For example, Collins and Hoyt (1972) had subjects write essays arguing against an open visitation policy in the dorms of their university (a counterattitudinal position). Subjects who believed that their essays would be used by the administration to affect the actual visitation policy (a foreseeable, undesired consequence), who accepted full responsibility for the content of the essays, and who received low financial inducement to write the essays showed greater attitude change than did subjects when any of these conditions were not present.

Cooper and Worchel (1970) had subjects perform a task similar to that of subjects in the original induced compliance experiment reported by Festinger and Carlsmith (1959). These subjects worked on a dull task and then agreed to try to convince a waiting subject (actually a confederate) that the experience had been highly enjoyable and interesting. Cooper and Worchel found that making the attitude-discrepant statement to the fellow college student (confederate) produced dissonance only when the confederate professed to be convinced by the statement. Only when the other person was convinced could an aversive event be said to have taken place. When this was not the case, subjects did not change their attitude about the task.

These studies, and others demonstrating that aversive consequences are necessary for dissonance arousal, are consistent with the general view that states that other important factors, in addition to a cognitive discrepancy, need to be present for dissonance to be aroused. The central tenet of the Cooper and Fazio (1984) model, however, is that dissonance is not motivated by inconsistency at all, but by the production of undesired consequences. We conducted a factorial experiment to test the proposition that merely bringing about aversive consequences, with or without discrepant cognitions or behavior, will activate the dissonance process and lead to attitude change. One group of subjects wrote a counterattitudinal essay, whereas a second group wrote a proattitudinal essay. Orthogonal to this manipulation, some subjects were told that their behavior would lead to an aversive event; others learned that no aversive event would occur. (In addition, two groups of subjects-one writing a proattitudinal essay and one a counterattitudinal essay-were run under no-choice conditions. We assumed that this lack of choice would lead subjects to avoid attributions of self-responsibility, thus precluding the need for attitude change about the consequences.) We predicted that those subjects who, under high choice conditions, wrote essays that they believed would bring about aversive consequences, would show dissonance-related attitude change, independent of whether the advocacy was attitude consistent or attitude discrepant.

\section{Method}

\section{Subjects}

Eighty-one students from a northeastern state university participated as subjects.

\section{Procedure}

Subjects came into the lab to participate in an experiment on the effects of persuasive communications on the decision making of committees. They were told that the researchers were interested in studying the decision processes ofa real committee after having collected nothing but laboratory evidence on the functioning of committees.

Subjects were then told that previous research had found that only the first and last several essays read by a committee were effective in convincing the committee. This so-called boomerang effect was explained to the subjects in this way:

The first couple of essays a committee reads seem to have the opposite effect of the way they were written. What I mean is that the first essays produce a boomerang effect. If they were written to support one side, they tend to convince the committee to take the other side.

Subjects were also told that the last couple of essays read by a committee convince the committee in a straightforward way. This description was included so that the persuasion direction manipulation was foreseeable by the subjects, but could not be known with certainty (cf. Goethals et al., 1979).

Subjects were asked to supply essays either strongly supporting or strongly opposing an increase in student fees. Students in general were strongly opposed to the increase.' They were told that these essays would be shown to the Dean's Committee on Policy and that the committee's decision processes would be studied. Thirty subjects were asked to write an essay supporting the fee increase (i.e., a counterattitudinal essay); another 30 were asked to take the opposing view (a proattitudinal essay).

All 60 of these subjects were given the choice of declining to write the essay. The experimenter commented that the subject might not support the position required to be taken and thus was free to decline to write the essay, but that it would be a big help if he or she would agree. All but I subject acceded to this request. (The data from the 1 subject who did not comply were not used in any of the analyses.)

After the essay was written, the experimenter returned and collected it. He then consulted a random numbers table and conducted the persuasion direction manipulation. He told the subject the order in which his or her essay would be read by the Dean's Committee. All subjects

' A survey of a random sample of the same student population conducted at a separate time found that subjects were generally opposed to an increase in student fees $(\mathrm{M}=6.1$ on a 31-point scale with endpoints labeled 1 [strongly disagree] and 31 [strongly agree]). 
were told that the committee would read 15 essays. In the boomerang condition, the experimenter told subjects that their essay would be the 2nd one read by the committee and reminded them that this would make it likely that their essay would contribute to a boomerang effect. In the no boomerang condition, the experimenter told subjects that their essay would be the 14th read by the committee and reminded them that this meant the essay would probably have a straightforward persuasion effect.

Finally, the subjects were asked to fill out a questionnaire giving their true attitudes on the issue and their thoughts about their essay. They were asked how they really felt about the fee increase, how much choice they had had in writing the essay, and how likely it was that their essay would contribute to a decision to increase student fees. Subjects answered these questions on 31-point scales, with high numbers signifying greater agreement with the increase in student fees (the counterattitudinal position), less perceived choice, and a belief that the essay was more likely to contribute to an increase in fees.

After completion of this measure, all subjects were debriefed as to the deception involved and informed of the study's true purpose.

Thus, the study's design was a 2 (essay position: proattitudinal-counterattitudinal) $\mathrm{x} 2$ (persuasion direction: boomerang-no boomerang) factorial design. In addition, there were two control groups. Previous research has shown that subjects not given a choice whether to write the essay do not feel responsible for any consequences produced and thus do not feel dissonance motivation (e.g., Cooper, 1971; Davis \& Jones, 1960). Therefore, two groups of 10 subjects each were run without a choice as to whether to write the essay. One group wrote a proattitudinal essay and one a counterattitudinal essay. Aside from the lack of choice, these conditions were identical to the proattitudinal-boomerang and counterattitudinal-no boomerang conditions, respectively.

\section{Results}

\section{Checks on Manipulations}

Aversiveness. We conducted 2 X 2 (Essay Position X Persuasion Direction) analysis of variance (ANOVA) on all data. There was a significant interaction for ratings of how likely it was that the essay would contribute to higher fees, $\mathrm{F}(1,56)=63.43$, $\mathrm{p}=$ .0001 . As predicted, proattitudinal essays were seen as being more likely to have this undesired consequence only when the essay was expected to produce a boomerang effect. On the other hand, when no boomerang effect was expected, only counterattitudinal essays were seen as being likely to have an aversive consequence (see Figure 1). Unexpectedly, there was a main effect for essay position. Counterattitudinal essays were seen in general as being more likely to produce an aversive consequence. We conducted a Newman-Keuls test to sort out the different means. The proattitudinal-boomerang and counterattitudinalno boomerang conditions were each significantly different from the proattitudinal-no boomerang and counterattitudinal-boomerang conditions (all ps $<.01, d f=56$ ), but they were not different from each other. Likewise, the proattitudinal-no boomerang and counterattitudinal-boomerang conditions did not differ. Thus, although on average the counterattitudinal essays seemed to be seen as producing more aversive consequences, examination of individual means shows that aversive consequences were seen as being likely only in those conditions in which subjects were told to expect their essays to convince the r_nmm_ittee to raise feec

We conducted Dunnett's tests with each of the low choice groups as a control group. For the proattitudinal-low choice group, we found significant differences in only the counterattitudinal-boomerang and proattitudinal-no boomerang conditions (both ps $<.01, d f=65$ ). The proattitudinal-low choice group expected a boomerang effect and thus should have expected aversive consequences. This is reflected in the fact that their ratings of the likelihood of aversive consequences differed from those in each of the conditions in which aversive consequences were not expected, but did not differ from those in the conditions in which aversive consequences were expected. The Dunnett's test using the counterattitudinal-low choice group showed similar results. This condition also differed only from the conditions in which aversive consequences were not expected (the counterattitudinal-boomerang and proattitudinalno boomerang conditions).

Choice. There was no difference in subjects' ratings of choice among the high choice groups $(\mathrm{M}=3.8), \mathrm{F}(1,56)<1$, ns. Planned comparisons of each low choice group with the average of the high choice groups showed that subjects in both the proattitudinal and counterattitudinal-low choice conditions reported having significantly less choice in writing the essay than did those in the high choice groups, proattitudinal $\mathrm{F}(1,74)=$ $181.84, p=.0001$; counterattitudinal $\mathrm{F}(1,74)=167.95, p=$ .0001 (see Table 1).

\section{Attitude Change}

We performed a $2 \times 2$ (Essay Position X Persuasion Direction) ANOVA on subjects' postessay attitudes toward the issue of whether the university should raise student fees. Remember that most students in the population were opposed to this increase, and that this was represented by lower numbers on a 31-point attitude scale. Therefore, higher numbers indicate greater agreement with the counterattitudinal position.

The interaction between essay position and persuasion direction was highly significant, $\mathrm{F}(1,56)=51.92, \mathrm{p}=.0001$ (see Figure 2). Neither the main effect for persuasion direction nor that for essay position approached statistical significance (Fs < I). Once again, we conducted a Newman-Keuls test, which revealed that there was counterattitudinal change only in the conditions in which aversive consequences were expected (counteratti.tudinal-no boomerang and proattitudinal-boomerang). These two conditions differed significantly from the two nonaversive conditions (proattitudinal-no boomerang and counterattitudinal-boomerang), but neither the two aversive conditions nor the two nonaversive conditions differed significantly from each other (all significant ps $<.01, d f=56$ ).

Dunnett's tests similar to those conducted on the ratings of the likelihood of aversive consequences were conducted on the attitude measure to compare the two low choice control groups with the high choice groups. The results of these tests showed that, among the high choice conditions, only the aversive consequence groups differed significantly from the low choice groups ( $p s<.01, d f=65)$. Thus, it appears that neither the low choice groups nor those high choice groups not expecting aversive consequences experienced cognitive dissonance.

\section{Aversive Consequences, Choice, and Attitude Correlations}

Both subjects' ratings of choice and their ratings of the likelihood of aversive consequences were significantly correlated 


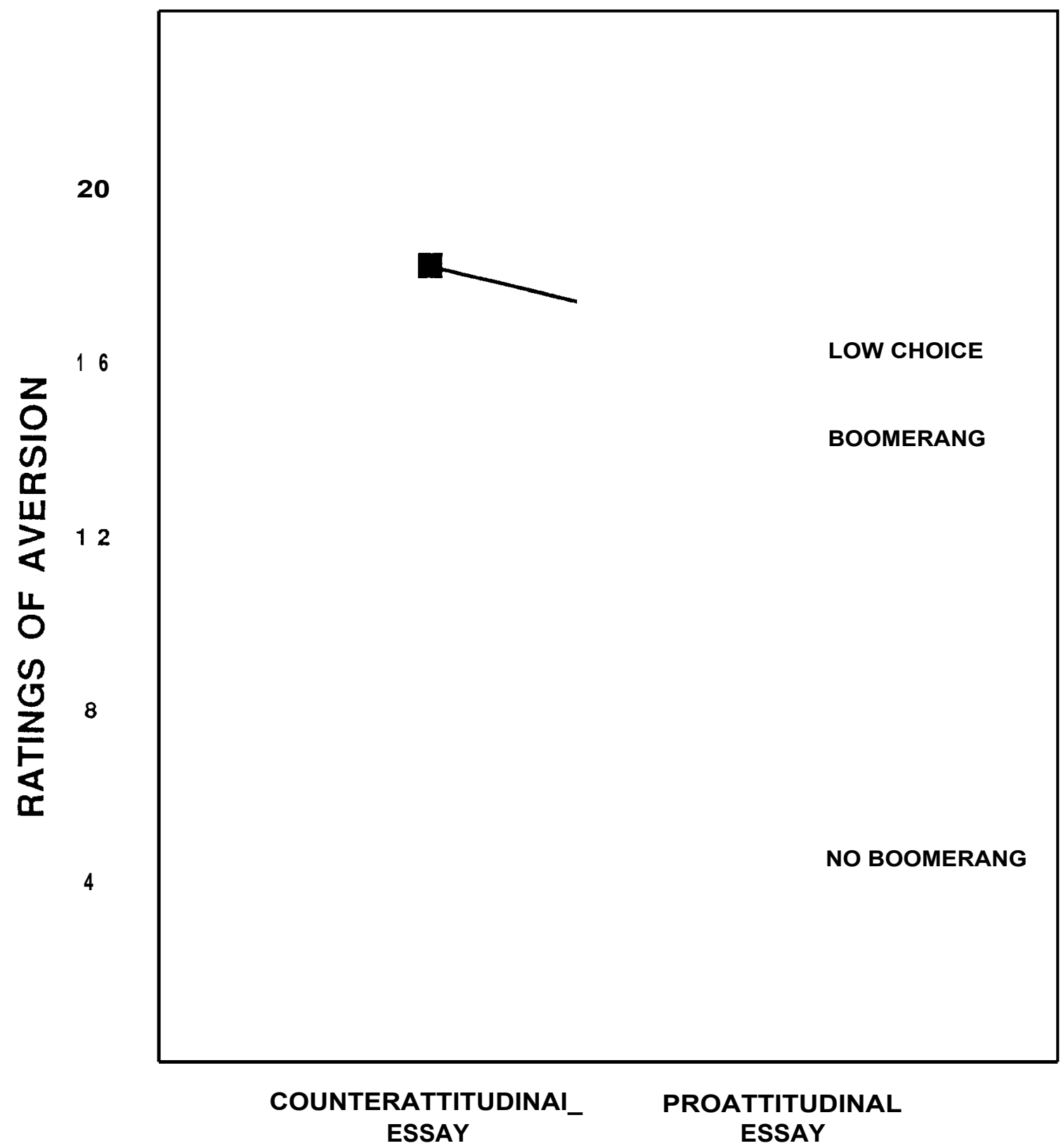

\section{POSITION}

Figure 1. Mean ratings of the likelihood of aversive consequences.

with attitude. For choice, where lower numbers indicated more perceived choice, there was a significant negative correlation with attitude $(\mathrm{r}=-0.319, \mathrm{p}<.005)$, indicating that the more choice subjects felt they had in writing the essay, the more likely they were to report counterattitudinal attitudes. Likewise, the more subjects expected their essay to have aversive consequences, the more likely they were to support the fee increase $(\mathrm{r}=.206, \mathrm{p}=.07)$. None of the within-cell correlations were significant.

\section{Discussion}

The data from this study provide the first empirical support for the proposition that the necessary and sufficient condition for the arousal of dissonance is the felt responsibility for bringing about an aversive consequence. In the present study, only when subjects felt that the essay they had written would lead to the creation of an unwanted, aversive situation (i.e., an increase in student fees) was there any apparent pressure for attitude 
Table 1

Mean Ratings of Choice

\begin{tabular}{lcc}
\hline & \multicolumn{2}{c}{ Position } \\
\cline { 2 - 3 } \multicolumn{1}{c}{ Condition } & Counterattitudinal & Proattitudinal \\
\hline Boomerang & 3.80 & 3.67 \\
No boomerang & 4.06 & 3.73 \\
Low choice & 21.1 & 16.5 \\
\hline
\end{tabular}

Note. Ratings were made on a 31-point scale on which lower numbers meant greater choice.

change. The study provides evidence consistent with a notion that has periodically been suggested in the dissonance literature (e.g., Collins \& Hoyt, 1972) and that forms the critical aspect of Cooper and Fazio's (1984) model of dissonance motivation.

These data help to clarify what is and is not the motivational basis of the dissonance effect. Most obviously, this study would seem to lay to rest the notion that dissonance is driven by a "master motive" for consistency. Our results provide strong evidence that even when there are no inconsistent behaviors, dissonance can be aroused. Rather, dissonance is a theory about the consequences of being responsible for negative events.

Our study should also help to rule out explanations of the dissonance effects based on an assumed impression management motive to appear consistent to an outside, high-powered person. Tedeschi and colleagues (Riess, Kalle, \& Tedeschi, 1981; Tedeschi \& Rosenfeld, 198 1; Tedeschi et al., 1971) have asserted that the sole reason for attitude change following inconsistent behavior is subjects' desire to make a good impression on an experimenter. According to this view, appearing inconsistent creates an impression in others that a person is foolish and unworthy. Following any form of counterattitudinal advocacy, then, subjects are said to be motivated to give the appearance of consistency between their behavior and their beliefs and so report changed attitudes; this is done solely for the purpose of presenting a positive image of themselves to the high-status experimenter. Several studies have taken issue with this impression management approach (see Cooper \& Fazio, 1984; Zanna $\&$ Cooper, 1976, for reviews). Our study clearly shows that dissonance occurs and attitude change results in the absence of any assumed perception of inconsistency on the subject 's part by the high-status experimenter. In fact, in the proattitudinal-boomerang condition, people actually changed the public presentation of their attitudes to render them inconsistent with their behavior. This is certainly antithetical to the presumed explanation of attitude change based on impression management.

Several recent theoretical statements have attempted to view dissonance in a larger motivational context that, like the Cooper and Fazio (1984) model, focuses on the implication of behavior for an evaluation of the self. Schlenker $(1982,1985)$ has argued for an identity-analytic model in which people are motivated to view themselves in a positive light. Such a motive was implicated by Aronson's earlier advocacy of the importance of selfesteem in producing dissonance (Aronson, 1969; Nei, Helmreich, \& Aronson, 1969). Steele and his colleagues (Steele, 1988; Steele \& Liu, 1981, 1983) have proposed that dissonanceproduced attitude change is a result of self-affirmation pro- cesses. According to this view, dissonance is created by behavior that has negative implications for the ego or self-system (cf. Greenwald \& Ronis, 1978). Inconsistent behavior produces dissonance because it makes a person feel stupid, evil, or both. A reaffirmation of the self becomes necessary, and by changing attitudes in the counterattitudinal direction, the self-system can be whole and unthreatened once again.

The present view is consistent in part with the self-affirmation view of dissonance processes. We agree with the major component of the self-affirmation account-that dissonance is aroused after inconsistent behavior not because of something intrinsically abhorrent about inconsistency but rather because of the meaning that the inconsistency may convey. Furthermore, we do not disagree with the self-affirmation view that dissonance motivation may be imbedded in a greater motivational system, and that other "extra dissonance" factors and behaviors may have an impact on the expression of dissonance, as has been demonstrated in several studies (Steele \& Liu, 1981, 1983). The dissonance motivation model is more specific, however; about what meaning must be granted to the behavior for dissonance to be aroused. It is our view that the behavior must bring about an event that a person would rather not have occur (Goethals \& Cooper, 1972), although whether the self is diminished or is made to feel ashamed, stupid, or guilty is not addressed by the dissonance motivation model. If the model suggests any specific self-attribution that would be made, it is that the person is less than self-efficacious. If we assume that people want to bring about desired consequences (and this is almost a tautology), then they would interpret feeling responsible for an undesired consequence to mean that they are not capable of working toward their desired ends.

On the other hand, it is not immediately clear that the selfaffirmation model would generate the predictions of the present study. According to that model, "dissonance motivation is stirred by the implication of the inconsistency that one is not adaptively or morally adequate" (Steele, 1988, p. 30). Any inconsistency that threatens the "integrity of the self" will lead to dissonance (pp. 30-31). However, the self-affirmation model does not specify what types of inconsistency would lead to a threat to self-integrity. In the study reported in this article, some subjects-those in the counterattitudinal-boomerang condition-behaved inconsistently, yet showed no evidence of cognitive dissonance. Is it less threatening to the self to write a statement that one does not believe or to write a consistent statement that brings about an unwanted event? Either of these events would seem to cause dissonance from a self-affirmation viewpoint, whereas the data from the present study indicate that only the latter leads to dissonance-produced attitude change.

Some readers may claim that our study does not eliminate the possibility that a discrepancy is necessary for the arousal of cognitive dissonance. These commentators would argue that our boomerang manipulation merely transformed the discrepancy from one between attitudes and behavior to one between attitudes and consequences (i.e., there is a discrepancy between "I am against increasing fees" and "I just contributed to bringing about a fee increase"). This may indeed be the case. However, we should point out that maintaining a discrepancy-based view of dissonance would require additional assumptions about the type of discrepancy necessary for dissonance arousal. The 


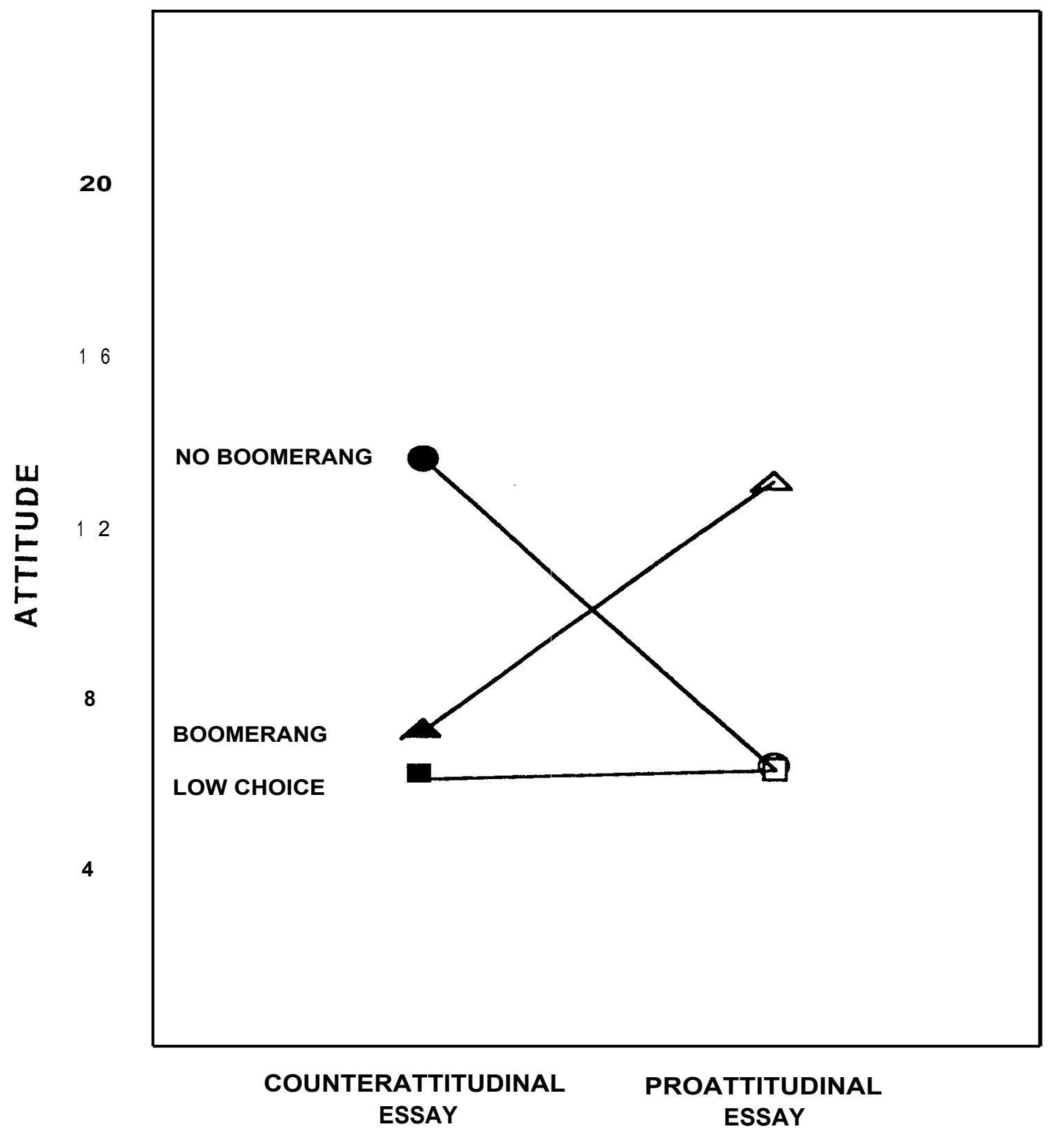

\section{POSITION}

Figure 2. Mean attitudes toward increasing student fees.

discrepancy would have to involve some outcome that threatens the person's identity as competently striving for desired ends, or be a discrepancy between the behavior and an attitude about some outcome. Our data show that dissonance processes can be aroused only when a discrepancy arises between the self's wish for some end and a behavior that brings about a discrepant end.

We would argue, however, that it is no longer viable to maintain that discrepancy is involved in the arousal of cognitive dis- sonance. Only with a complicated twisting and limiting of the notion of discrepancy can this view be maintained. By limiting the type of discrepancy in these ways, the theory's usefulness is severely limited. When dissonance theory began to be laden with additional constraints on the arousal of dissonance (i.e., choice, foreseeability, etc.), the general applicability that had given the theory its power was diminished. It is time to restructure our view of the arousal of dissonance and to incorporate 
dissonance research into a theory with a more global predictive and interpretive power by abandoning the notion that discrepancy is necessary (cf. Greenwald et al., 1986).

The interpretation of dissonance as a motivation that results from placing responsibility for aversive consequences onto the self broadly expands the ways in which dissonance can be applied. Various behaviors beyond the traditional domain of attitude change can then be seen as deriving from dissonance. Consider the following example: A person is asked by a friend for a favor. The person fails to fulfill the request, resulting in adverse consequences for the friend and the friend's opinion of the person. Here, then, the undesired consequence involves hurting an esteemed other (cf. Cooper, Zanna, \& Goethals, 1974; Davis \& Jones, 1960), and one can assume that dissonance will be aroused. The options for reducing the dissonance are many. Of course, the actor's opinion of the friend or of the importance of the friend's opinion could change. The actor could thereby transform the friend from an esteemed other into a nonesteemed other.

Other options could involve reducing the responsibility that the actor feels for the consequence. Although the notion of responsibility reduction as dissonance reduction is beyond the scope of this article, we mention it here because it is a somewhat neglected area of dissonance research (cf. Calder et al., 1973; Cooper \& Scher, in press, for more detailed discussions). Suffice it to say that any way a person could reduce perceptions that the self is responsible for the consequence should lead to dissonance reduction. For example, Zanna and Sande (1987) found that when aversive consequences were brought about by a group, group members experienced less dissonance because they were able to diffuse the responsibility, sharing it with others in the group. Changing perceptions of how much choice or foreseeability the person had would be another way for an individual to reduce responsibility for bringing about an aversive event. It could also involve some way of sharing the responsibility with others (including the friend or the experimenter in traditional tests of the dissonance phenomena). In short, any way in which the actor can "renegotiate" his or her perceptions of the situation could reduce dissonance.

Another example of a situation in which people might bring about an aversive outcome and thus feel dissonance is one in which people desire to maintain a certain position or self-image (Goffman, 1959), but take some action that violates it. Here the undesired consequences are embarrassment, a loss of esteem, and perhaps a loss of some objective benefits that accrue from the desired self-image. Dissonance reduction might involve changing attitudes about the desirability of the position being maintained and about the value of the other benefits.

Rhodewalt and his colleagues (Jones, Rhodewalt, Berglas, \& Skelton, 1981; Rhodewalt \& Agustsdottir, 1986) have demonstrated that when a person is induced to present a negative selfi mage, then responsibility-related (high-choice) variables influence the extent to which that negative image is internalized, becoming part of the self-image. Here, the undesired consequence is the development of a poor image of the actor in the eyes of the audience.

To conclude, we have demonstrated that in some situations the perception of responsibility for aversive consequences is a sufficient cause for the arousal of cognitive dissonance. In these settings, inconsistent cognitions are not necessary. The fact that a person causes some undesired event and makes self-attributions of responsibility for that event would seem to be a more ${ }^{i}$ mportant determinant of cognitive dissonance-induced attitucle change than would discrepant cognitions.

\section{References}

Aronson, E. (1969). The theory of cognitive dissonance: A current perspective. In L. Berkowitz (Ed.), Advances in experimental social psychology (Vol. 4, pp. 1-34). New York: Academic Press.

Aronson, E., \& Carlsmith, J. M. (1963). Effect of severity of threat on the valuation of forbidden behavior. Journal of A bnormal and Social Psychology, 66, 584-588.

Calder, B. J., Ross, M., \& Insko, C. A. (1973). Attitude change and attitude attribution: Effects of incentive, choice, and consequences. Journal of Personality and Social Psychology, 25, 84-99.

Carlsmith, J. M., Collins, B., \& Helmreich, R. L. (1966). Studies in forced compliance: 1 . The effect of pressure for compliance on attitude change produced by face-to-face role playing and anonymous essay writing. Journal of Personality and Social Psychology, 4, 1-13.

Collins, B. E. (1969). Attribution theory analysis of forced compliance. Proceedings of the 77th Annual Convention of the American Psychological A ssociation, 4, 309-310.

Collins, B. E., \& Hoyt, M. G. (1972). Personal responsibility for consequences: An integration and extension of the "forced compliance" literature. Journal of Experimental Social Psychology, 8, 558-593.

Cooper, J. (1971). Personal responsibility and dissonance: The role of foreseen consequences. Journal of Personality and Social Psychology, $18,354-363$.

Cooper, J., \& Fazio, R. H. (1984). A new look at dissonance theory. In L. Berkowitz (Ed.), Advances in experimental social psychology (Vol. 17, pp. 229-266). New York: Academic Press.

Cooper, J., \& Goethals, G. R. (1974). Unforeseen events arid the elimination of cognitive dissonance. Journal of Personality and Social Psychology 29, 441-445.

Cooper, J., \& Scher, S. J. (in press). Actions and attitudes: The role of responsibility and aversive consequences in persuasion. In T. Brock \&. S. Shavitt (Eds.), The psychology of persuasion. San Francisco: Freeman.

Cooper, J., \& Worchel, S. (1970). Role of undesired consequences in arousing cognitive dissonance. Journal of Personality and Social Psychology, 16, 199-206.

Cooper, J., Zanna, M. P., \& Goethals, G. R. (1974). Mistreatment of an esteemed other as a consequence affecting dissonance reduction. Journal of Experimental Social Psychology, 10, 224-233.

Davis, K., \& Jones, E. E. (1960). Changes in interpersonal perception as a means of reducing cognitive dissonance. Journal cf Abnormal and Social Psychology, 61, 402-410.

Festinger, L. (1957). A theory of cognitive dissonance. Stanford, CA: Stanford University Press.

Festinger, L., \& Carlsmith, J. M. (1959). Cognitive consequences of forced compliance. Journal of Abnormal and Social Psychology, 58, 203-210

Festinger, L., Riecken, H., \& Schachter, S. (1956). When prophecy fails. Minneapolis: University of Minnesota Press.

Goethals, G. R., \& Cooper, J. (1972). The role of intention and postbehavioral consequences in the arousal of cognitive dissonance. Journal of Personality and Social Psychology 23, 293-301.

Goethals, G. R., Cooper, J., \& Naficy, A. (1979). Role offoreseen, foreseeable, and unforeseeable behavioral consequences in the arousal of $\mathrm{co}^{\mathrm{g}}$ nitive dissonance. Journal of Personality and Soria/ Pcyrhologv 37, $1179-1185$.

Goffman, E. (1959). The presentation of self in everyday life. Garden City, NY: Doubleday. 
Greenwald, A. G., Pratkanis, A. R., Leippe, M. R., \& Baumgardner, M. H. (1986). Under what conditions does theory obstruct research progress? Psychological Review, 93, 216-229.

Greenwald, A. G., \& Ronis, D. L. (1978). Twenty years of cognitive dissonance: Case ,.... of the evolution of a theory. Psychological eview, 85, 53-57.

Hoyt, M. F., Henley, M. D., \& Collins, B. E. (1972). Studies in forced compliance: Influence of choice and consequences on attitude change. Journal ofPersonality and Social Psychology, 23, 205-210.

Jones, E. E., Rhodewalt, F., Berglas, S., \& Skelton, J. A. (1981). Effects of strategic self-presentation on subsequent self-esteem. Journal of Personality and Social Psychology, 41, 407-421.

Linder, D., Cooper, J., \& Jones, E. E. (1967). Decision freedom as a determinant of the role of incentive magnitude in attitude change. Journal ofPersonality and Social Psychology, 6, 245-254.

Nei, E., Helmreich, R., \& Aronson, E. (1969). Opinion change in the advocate as a function of the persuasibility of his audience: A clarification of the meaning of dissonance. Journal ofPersonality and Social Psychology, 12, 117-124.

Rhodewalt, F., \& Agustsdottir, S. (1986). Effects of self-presentation on the phenomenal self. Journal ofPersonality and Social Psychology, 50, 47-55.

Riess, M., Kalle, R. J., \& Tedeschi, J. T. (1981). Bogus pipeline, attitude assessment, impression management, and misattribution in induced compliance settings. Journal ofSocial Psychology, 115, 247-258.

Schlenker, B. R. (1982). Translating action into attitudes: An identityanalytic approach to the explanation of social conduct. In L. Berkowitz (Ed.), Advances in experimental social psychology (Vol. 15, pp. 193-247). New York: Academic Press.

Schlenker, B. R. (1985). Identity and self-identification. In B. R. Schlenker (Ed.), The self and social life (pp. 65-99). New York: McGrawHill.
Sherman, S. J. (1970a). Attitudinal effects of unforeseen consequences. Journal ofPersonality and Social Psychology 16, 510-519.

Sherman, S. J. (1970b). Effects of choice and incentive on attitude change in a discrepant behavior situation. Journal ofPersonality and Social P ychology 15, 245251

Steele, C. M. (1988). The psychology of self-affirmation: Sustaining the integrity of the self. In L. Berkowitz (Ed.), Advances in experimental social psychology (Vol. 21, pp. 261-302). New York: Academic Press.

Steele, C. M., \& Liu, T. J. (1981). Making the dissonant act unreflective of the self: Dissonance avoidance and the expectancy of a value-reaffirming response. Personality and Social Psychology Bulletin, 7, 393-397.

Steele, C. M., \& Liu, T. J. (1983). Dissonance processes as self-affirmation. Journal of Personality and Social Psychology, 45, 5-19.

Tedeschi, J. T., \& Rosenfeld, P. (1981). Impression management and the forced compliance situation. In J. T. Tedeschi (Ed.), Impression management theory and social psychological research (pp. 147-177). New York: Academic Press.

Tedeschi, J. T., Schlenker, B. R., \& Bonoma, T. V. (1971). Cognitive dissonance: Private ratiocination or public spectacle? American Psychologist, 26. 685-695.

Zanna, M. P., \& Cooper, J. (1976). Dissonance and the attribution process. In J. H. Harvey, W. J. Ickes, \& R. F. Kidd (Eds.), New directions in attribution research (Vol. 1, pp. 199-217). Hillsdale, NJ: Erlbaum.

Zanna, M. P., \& Sande, G. N. (1987). The effects of collective actions on the attitudes of individual group members: A dissonance analysis. In M. P. Zanna, J. M. Olson, \& C. P. Herman (Eds.), Social influence: The Ontario Symposium (Vol. 5, pp. 151-163). Hillsdale, NJ: Erlbaum.

Received December 24, 1987

Revision received October 21, 1988

Accepted October 25, 1988 